\title{
Purdue attacked over fusion inquiry
}

Nine months after serious allegations were levelled against high-profile 'bubble fusion' research at Purdue University in West Lafayette, Indiana, the institution is being criticized by researchers within and outside its walls for its apparent failure to respond.

Lefteri Tsoukalas, head of the nuclear-engineering school where the work was carried out, resigned his position in October, expressing disappointment over the slow pace and secrecy of the university's response. Last week, he made his concerns public. In an open letter from his lawyer to Purdue's provost Sally Mason, Tsoukalas called for the university to release an interim report on its progress. "Purdue is a great public university, not a private club," he told Nature.

In response, Purdue spokesman Joe Bennett confirmed for the first time that there is an ongoing inquiry at the university. "We are not going to have any comment while this is under way, he said.

The allegations relate to the work of Rusi Taleyarkhan, a professor of nuclear engineering at Purdue. Since 2002, Taleyarkhan has published three major papers claiming to have achieved nuclear fusion by using sound waves to collapse bubbles in deuterated liquids, raising the prospect of a virtually unlimited energy source $^{1-3}$. Tsoukalas' letter comes days after the announcement that a Texas physicist, working with Taleyarkhan in his lab, has achieved similar results (see 'Bubbling up').

In March, Nature reported concerns over the validity and reliability of Taleyarkhan's work ${ }^{4}$, based on statements made by members of Purdue's nuclear-engineering school, as well as an analysis by physicist Brian Naranjo at the University of California, Los Angeles. Naranjo's study ${ }^{5}$ showed that the spectrum of neutrons produced by Taleyarkhan's experiments fits not fusion, but the radioactive decay of californium, a standard lab material.

Purdue quickly announced that a university panel would review Taleyarkhan's work and make the findings public.

In June, it said the review was complete but that its findings and any future steps would remain confidential. Since then, Purdue has released no information (until Bennett's comment this week) about whether or not
"I'm not horrified they didn't respond, but it is in keeping with their other foot-dragging." by Taleyarkhan. Suslick has received no reply from Purdue.

"They have to be careful what they say in case the accusations are false, so I'm not horrified they didn't respond," Suslick says. "But it is in keeping with their other foot-dragging. At some point they have to say that they have had an investigation and that they either exonerated him or didn't."

Internally, misconduct allegations have been made that centre on the claim that Taleyarkhan wrote up work with his postdoc Yiban Xu claiming to have achieved bubble fusion, then left his own name off the resulting paper (he is listed in it is investigating Taleyarkhan. Tsoukalas says he decided to write to Purdue because he had received no adequate response to his concerns since he first expressed them in March. Purdue's policies suggest a timeline of three months for investigating misconduct allegations.

Other researchers in the field are also far from impressed by the apparent lack of progress. Ken Suslick, for example, a professor of chemistry at the University of Illinois at Urbana-Champaign, sent a confidential note in June to Purdue's associate vice-president for research, Peter Dunn, stating that he believed Taleyarkhan's research claims are fraudulent. Suslick detailed a number of reasons for his view, including Naranjo's analysis; the fact that other teams were unable to repeat the work; and an experimental demonstration he attended at which he believed data were being "cherry-picked" the acknowledgments) ${ }^{6}$. Taleyarkhan cited this study in a later paper ${ }^{3}$ as independent confirmation of his work.

Taleyarkhan has indicated that he is unable to respond to requests for comment about the various allegations because this might violate university's confidentiality procedures. But Taleyarkhan's co-author, Richard Lahey of Rensselaer Polytechnic Institute in Troy, New York, has defended him. "As far as I have been told, [the data] were taken by the authors of this paper," Lahey says.

Concerns have been raised, however, over the fact that data published in Xu's paper are apparently identical to separate data reported by Taleyarkhan. Xu included a figure showing microphone measurements taken during a fusion experiment at Purdue. It includes data that look identical to those reported by Tale-

\section{Actions speak louder than images}

\section{NEW YORK}

Canbrain scans of a racist, liar or psychopath accurately tell whether that person will persecute, fib or kill? No, say experts in the ethics of neuroscience, who are increasingly concerned that such images will be used to make dangerous legalor social judgements aboutpeople's behaviour. They say it is time for scientists, lawryers and philos ophers to speak up about the limitations of such techniques.

"Lawyers want to know 'Can I put somebody on the scanner and tell if they're racist?" "says Elizabeth Phelps, a psychologist and neuroscientist at New York

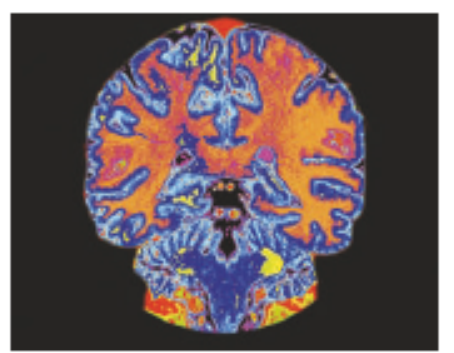

Handle withcare:can brain scans really identify antisocial people?
University whohas studied the brain's response torace. "Weas a group of scientists have to be able to say that we can't make that distinction." Phelps spoke at a panel discussion on the emerging field of neuroethics held in New York last week.

Neuroscientists increas ingly use technologies such as functional magnetic resonance imaging to see how blood flow in the brain changes when we see pictures, recall memories or make decisions. But these images are prompting concerns about how they might be over-interpreted or misused (see Nature 435, 254-255; 2005).

Outside the lab, neuroimaging is being touted as a way to detect lies (see Nature 437, 457; 2005) or to predict what shoppers might buy. There have been suggestions that brain imaging could be used to screen police officers for race bias by showing them faces of particular ethnicities.

But most scientists say that studies of behavioural or physical responses - for example, a person's 


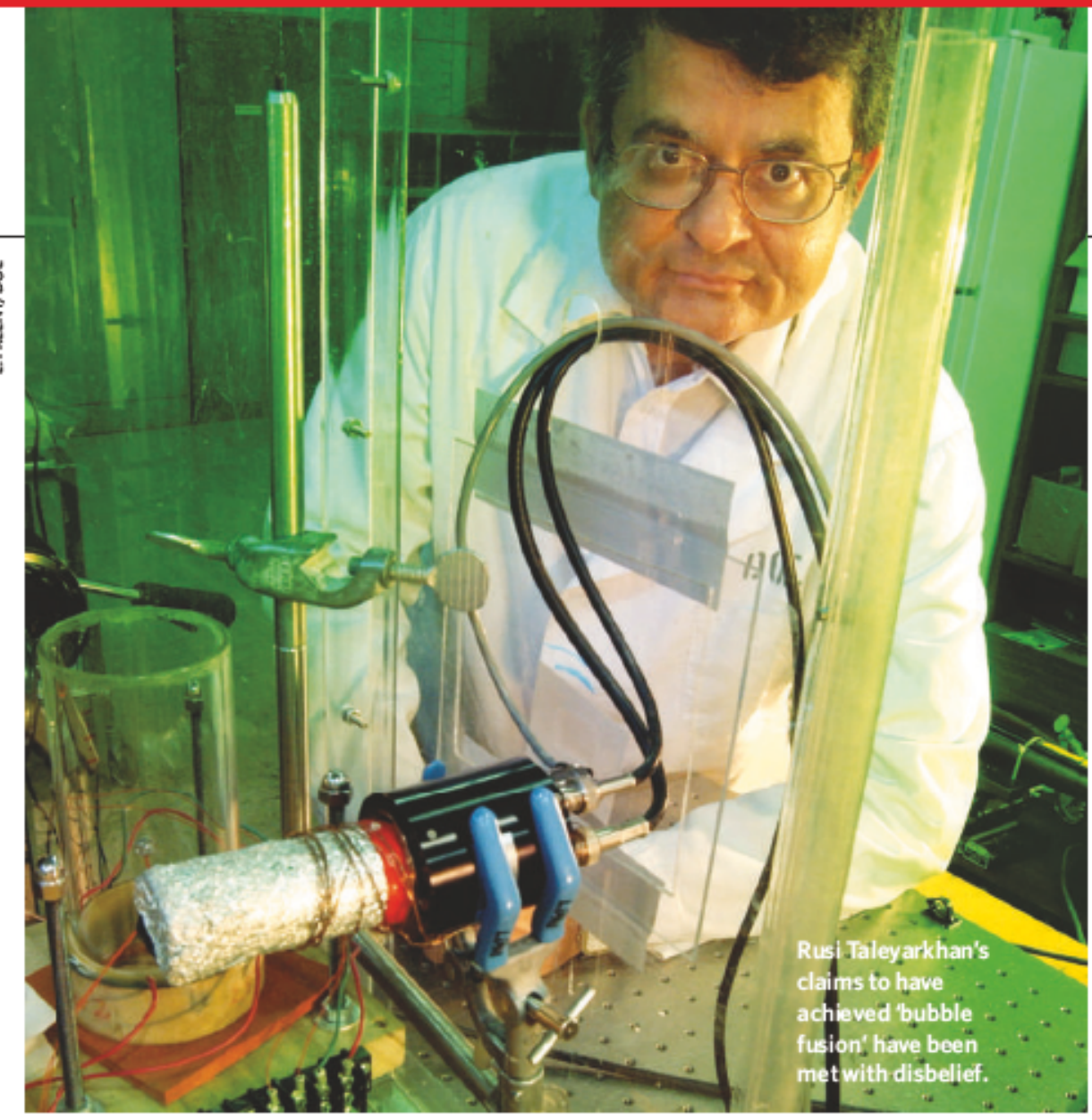

yarkhan from a prior experiment carried out at Oak Ridge National Laboratory in Tennessee? where he previously worked, as well as those presented by him in a slideshow for DARPA, the Pentagon's research agency, in 2005. The results from Oak Ridge and Purdue were reported to have been produced under different experimental conditions, and the papers have no common authors. Xu has defended the measurements as his own, but dedined to say who wrote the paper.

Nature showed the data to three scientists from different groups in the field. All con- cluded that the measurements must have been taken from the same experiment, because different acoustic cells tend to have characteristic outputs. Lahey disagrees. "If the test sections were of the same design (which they were), the response during cavitation events will be essentially the same, he says.

For Tsoukalas, the lack of word from Purdue is damaging the reputations of all concerned. In the letter to Mason, Tsoukalas's lawyer, Philip Michael, writes: "Significant time has now elapsed since the Purdue Administration made any public statement on the progress of

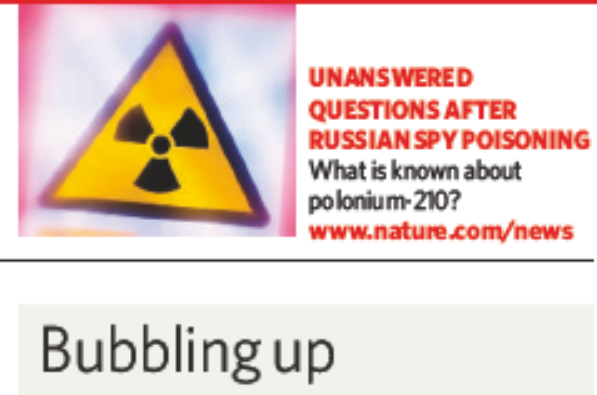

A physicist at a small Texas college says he has reproduced bubble fusion with the help of Rusi Taleyarkhan.

The work was presented last month at the American Nuclear Society's meeting in Albuquerque, New Mexico, by Edward Forringer of LeTourneau University - a small, evangelical Christian school in Longview. The results were obtained in Taleyarkhan's lab at Purdue University using his equipment, and Forringer believes they tentatively confirm that bubble fusion is occurring.

Forringer went to Taleyarkhan's labin May after approaching him abouthiswork. Working closely with Taleyarkhan, Forringer says he reproduced Taleyarkhan's earlier results. Forringer adds he didnot see any signthat the neutronshe detectedmighthave come from a californium source, as Taleyarkhan's critics have suggested, rather than fusion. But he agrees that reproducing the workina different labis what is needed. "We're certainly going to try todo that," he says.

Geoff Brumfiel

its investigation, inquiry or examination of the allegations of misconduct which Professor Tsoukalas and other researchers have made... we believe that it is appropriate to ask for an interim report."

Eugenie Samuel Reich

1. Taleyarkhan R. P.etal. Sdence 295, 1868-1873(2002)

2. Taleyarkhan R. P.etal. Phys Rex E 69, 036109 (2004)

3 Taleyarkhan R. P.etal. Phys Rex Lett. 96,034301 (2006)

4. Reich, E S Nature dok:101088/news060306-1 (2006).

5. Naranja. B. Phys Rex Lett. 97, 149408 (2006)

6. Xu, Y \& Butt, A.Nucl. Eng Des. 235, 1317-1324 (2005)

7. Taleyarkhan, R. P, Lahey, R T. \& Nigmatulin, R.I.Multiphase Sci. Technal. 17, 191-224 (2005) reaction to differentraces in real life - should trump imaging every time. That's because inter preting brain scans, and correlating them to actions, is inaccurate at best. All we can really gain from suchstudies is a more nuanced understanding of behaviour, says Phelps.

The persuasiveness of brain scanshas already drawn them into the court-room. In a landmark case in the US Supreme Court in March 2005, several leading scientific groups, including the American Medical Association, the American Psychiatric As sociation and the National Mental Health Association, filed briefs to support the premise that teenagers are less rational than adults.

The data included a brainimaging study showing that the prefrontal cortex, which governs impulse control and reasoning develops late in adolescence (see Nature 442, 865-867; 2006), and could explain some irrational aspects of teenage behaviour.

Many groups thought thisstudy could help rule against the death penalty. But although the court ruled against the death penalty for those younger than 18 , it chose not to cite the brain-imaging study, relying instead on behavioural studies that showed adolescents are more impulsive, more vulnerable to peer pressure and more affected by stress.
Stephen Morse, a profes sor of law and psychiatry at the University of Pennsylvania, Philadelphia, thinks it was a wise decision. Although the imaging study helped to explain why a particular group might have different behaviour, the behaviour itself is more important than the changes seen in the brain, hesays. Citing the study would have given it too much credibility, he adds, and opened the door for further claims that imaging predicts behaviour. "The legal and moral claims beingmade [from imaging studies involving very few people] are far tooextensive."

Morse is a founding member of the Neuroethics Society, set up earlier this year by a group of lawyers, philosophers and scientists to address issues raised by the use of brain scans and other future applications of neuroscience (see Nature 441, 907; 2006). Many neuroscientists are concerned about inappropriate applications of their research, but they rarely come out and say so. Scientists should speak up, butit will also take lawyers and sociologists tolay out the concerns, says Morse. "We need scientists tosay what they know and what they don'tknow," he says. "But the implications are nota science question, they are a moral question, a social question, a legal question." Apoorva Mandavilli 